\title{
Felten, Franz J., Jarnut, Jörg, Padberg, Lutz E. von, Bonifatius - Leben und Nachwirken. Die Gestaltung des christlichen Europa im Frühmittelalter
}

\section{Charles Mériaux}

\section{(2) OpenEdition \\ Journals}

Édition électronique

URL : http://journals.openedition.org/ifha/1642

DOI : $10.4000 /$ ifha. 1642

ISSN : 2198-8943

Éditeur

IFRA - Institut franco-allemand (sciences historiques et sociales)

Référence électronique

Charles Mériaux, «Felten, Franz J., Jarnut, Jörg, Padberg, Lutz E. von, Bonifatius - Leben und

Nachwirken. Die Gestaltung des christlichen Europa im Frühmittelalter ", Revue de l'IFHA [En ligne], Date de recension, mis en ligne le 01 janvier 2008, consulté le 22 septembre 2020. URL : http:// journals.openedition.org/ifha/1642 ; DOI : https://doi.org/10.4000/ifha.1642

Ce document a été généré automatiquement le 22 septembre 2020.

(CIFHA 


\title{
Felten, Franz J., Jarnut, Jörg, Padberg, Lutz E. von, Bonifatius - Leben und Nachwirken. Die Gestaltung des christlichen Europa im Frühmittelalter
}

\author{
Charles Mériaux
}

Voici publiés les actes du colloque tenu à Mayence du 2 au 5 juin 2004 à l'occasion du 1250e anniversaire de la mort de saint Boniface en Frise (754). Cette commémoration a donné lieu à une vague de publications dont le Bulletin s'est fait régulièrement l'écho ces dernières années. Le présent volume regroupe 22 contributions, majoritairement en langue allemande (mais une est rédigée en français et cinq le sont en anglais) réparties en sept sections correspondant aux grands champs de l'activité déployée par Boniface sur le continent de 719 - date de sa première rencontre à Rome avec le pape Grégoire II - à 754. Il est ainsi question dans un premier temps de la conversion des peuples païens. Les exposés généraux de L. Milis et A. Angenendt sont complétés par les approches plus ciblées de S. Lebecq sur le paganisme frison et de H. Steuer sur le paganisme saxon. Méthodes et techniques missionnaires sont présentées par W. Haubrichs et M. Richter (tous deux sur les problèmes linguistiques), C. Nolte (sur les correspondantes anglosaxonnes de Boniface qui encouragèrent sa mission continentale), L. von Padberg (sur les fondements théologiques de la mission bonifacienne), R. Meens (sur les pénitentiels) et $\mathrm{Y}$. Hen (sur la liturgie). Un exposé plus général de J. Semmler revient également sur l'activité missionnaire et pastorale des moines entre le Ve et le IXe s. La réforme de l'Église franque, la mise en place des institutions ecclésiastiques en Germanie et la coopération avec les autorités politiques sont ensuite abordées à travers des thèmes particuliers comme les rapports que Boniface entretint avec Charles Martel, moins explorés que ceux qui lièrent le missionnaire à Carloman et Pépin III (M. Becher) ; avec l'aristocratie franque (S. Airlie) ; avec Rome (T. Noble). Sont également envisagées l'activité conciliaire de Boniface (U. Nonn), la fondation de Fulda (D. Geuenich), la 
création des diocèses bavarois telle que la présentent les sources hagiographiques (St. Freund). L'ouvrage s'achève comme il se doit sur trois contributions évoquant le souvenir laissé par Boniface dans l'hagiographie (S. Haarländer), la littérature du XIXe s. (R. Schieffer) ainsi que sur les interprétations que l'on fit du personnage dans l'immédiat après-guerre, à l'occasion des fêtes jubilaires de 1954. Un copieux index facilite l'usage du volume dont on peut toutefois regretter qu'il ne soit pas illustré de quelques cartes. Pour conclure, on fera remarquer que la plupart des auteurs avaient déjà eu l'occasion de s'exprimer à propos de Boniface. Tout cela était néanmoins très dispersé. Ce volume a ainsi le grand mérite d'offrir un beau bouquet de contributions parfaitement à jour qui, s'ajoutant aux actes du colloque de Bonn sur les événements de 751 et 754 (Matthias Becher et Jörg Jarnut (dir.), Der Dynastiewechsel von 751. Vorgeschichte. Legitimationsstrategien und Erinnerung, Münster : Scriptorium, 2004 : voir BullMHFA, 41, 2005, p. 365-366), mettent désormais à la disposition des historiens, chercheurs ou enseignants, un solide bilan des profondes transformations politiques et religieuses que connaissait l'Europe occidentale au milieu du VIIIe s. 